\title{
CONSIDERING NEW PARAMETERS IN THE STUDY OF ATMOSPHERIC IMPACTS AT ADMIRALTY BAY
}

http://dx.doi.org/10.4322/apa.2014.023

\author{
Eduardo Delfino Sodré ${ }^{1}$, Heitor Evangelista ${ }^{1, *}$, Lavínia Brito ${ }^{1}$, Sergio Machado Corrêa ${ }^{2}$ \\ 'Laboratório de Mudanças Globais e Radioecologia -DBB, Instituto de Biologia Roberto Alcântara Gomes -IBRAG, \\ Universidade Estadual do Rio de Janeiro - UERJ, Rio de Janeiro, RJ, Brazil \\ ²Departamento de Química e Ambiental, Faculdade de Tecnologia, \\ Universidade Estadual do Rio de Janeiro -UERJ, Resende, RJ, Brazil \\ *e-mail: evangelista.uerj@gmail.com
}

\begin{abstract}
The purpose of this research is to deepen the investigation of atmospheric impact as a result of aerosol and gas emissions at Comandante Ferraz Brazilian Antarctic Base (henceforth EACF). As a consequence of a campaign during 2009/2010 summer and re-analysis of 1998 filters (whereby there became available an annual set of continuous samples), levoglucosan (the product cellulose pyrolysis) as an indicator of burning of organic material by the Brazilian Station was verified. The numeric model of atmospheric dispersion used for Admiralty Bay was suitable for study of the impact on the atmosphere in Admiralty Bay and in zoned areas of biological importance within the Antarctic Specially Managed Area of King George Island, using a simulation with stations and ships operating simultaneously. The preliminary results of the chemical analyses for carbonyls and BTEX have shown that the direct atmospheric impact zone of EACF, due to these chemicals, is restricted to a radius of a maximum of $400 \mathrm{~m}$, falling sharply in all directions
\end{abstract}

Keywords: King George Island, atmospheric impact, air polution, levoglucosano, BETEX

\section{Introduction}

An Antarctic Specially Managed Area (ASMA) of greater interest for the Brazilian Antarctic Programme has been delineated around Admiralty Bay and covers the location of 2 permanent research stations: EACF (Brazil) and Arctowski (Poland) and 2 of a smaller size, which operate only during the austral Summer: Machu Picchu (Peru) and Pieter J. Lenie-Copacabana (U.S.A), (Weber \& Montone, 2006). All these stations have power generating systems operated on the basis of the burning of fossil fuels (with the exception of Copacabana) and also incinerate organic waste. These operational pattern make the stations sources of research related to local pollution. The Brazilian base is the one which sustains a greater amount of human activity due to the great number of research scientists and technical support professionals, who are based there every year, together with their logistical maintenance support systems, personnel transport carriers, and materials. Admiralty Bay also receives several tourist ships that contribute to the increase of the local atmospheric pollution. The orography of the region is characterised by fjords surrounded by mountainous areas, which results in a large basin area making difficult the dispersion of pollutants generated there, especially during periods of high atmospheric stability. In this research work, we present the results of new simulations using the mathematical model of atmospheric dispersion presently in use, ISCST3 (Industrial Source Complex Short Term Version 3), and the employment of chemical markers (levoglucosan, total BTEX and total carbonyls) representative of the anthropic activities at ASMA. 


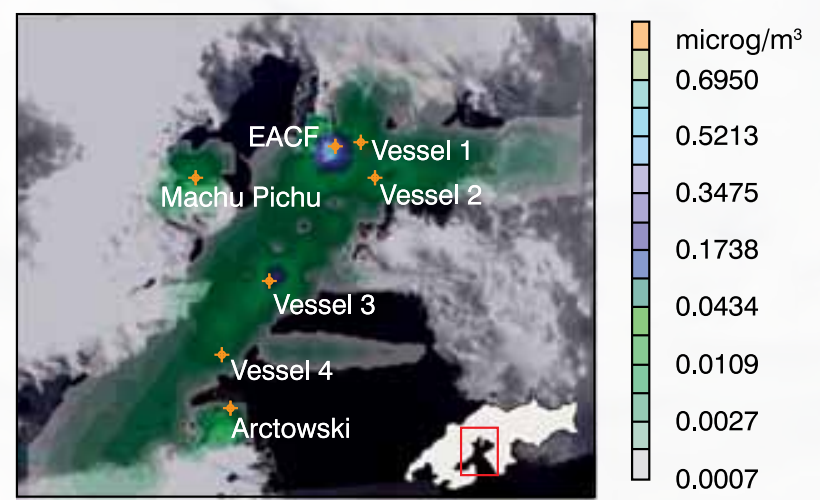

Figure 1. A modelled scenario of atmospheric dispersion using multiple sources in the interior of Admiralty Bay/King George Island.

\section{Preliminary Results}

\section{Atmospheric dispersion model}

The mathematical atmospheric pollutant dispersion models are important tools for understanding the behaviour of some gaseous and particle pollutants using data from the study of topography, emissions and meteorology. These models estimate the impact of one or more sources on the air quality of a certain region. The dispersion model used in this research was the ISCST3 (Industrial Source Complex - Short Term
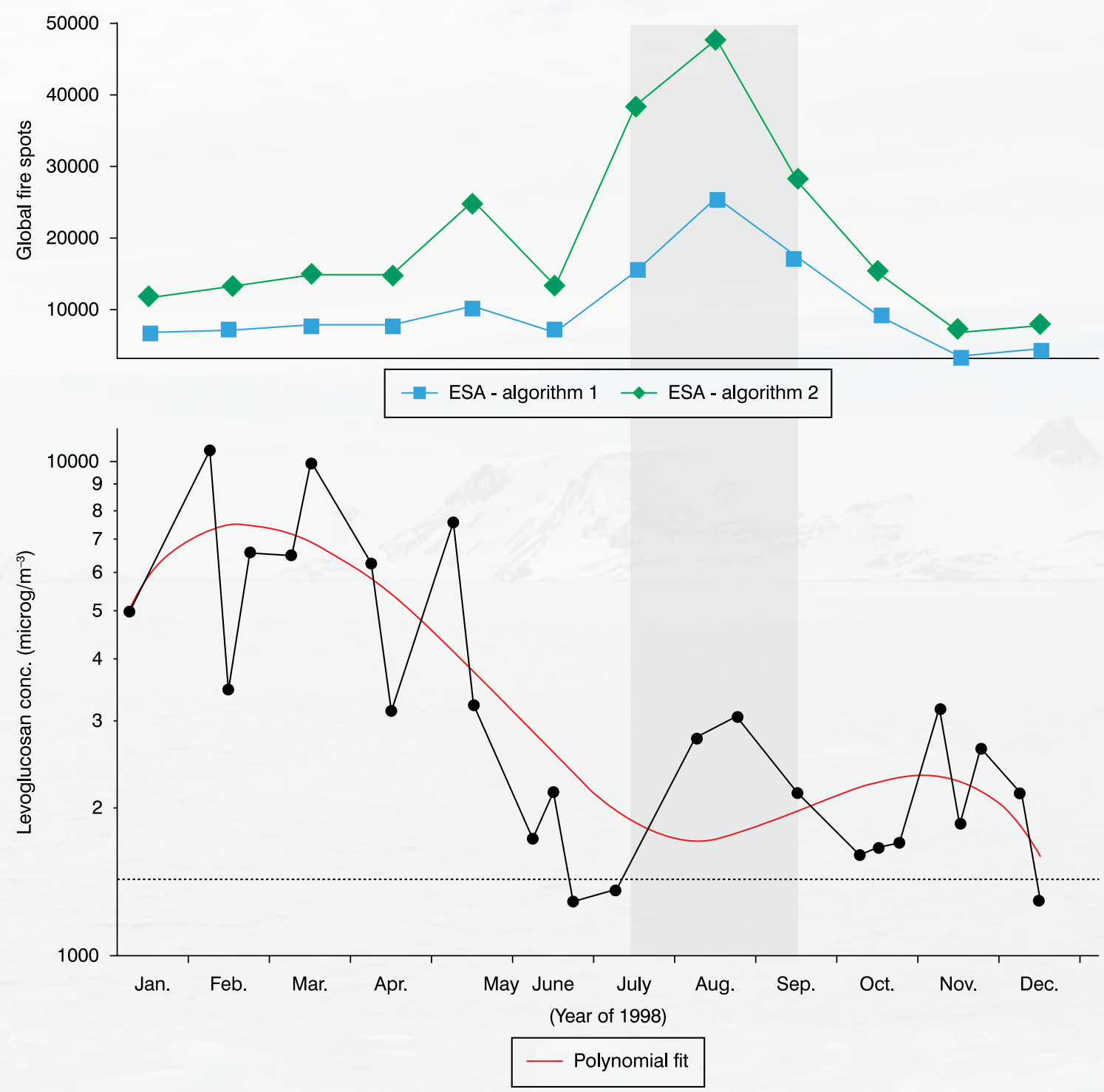

Figure 2. (Upper) seasonal average of global fire spots; (bottom) inter-annual concentrations of Levoglucosan in 1998 measured at EACF. 


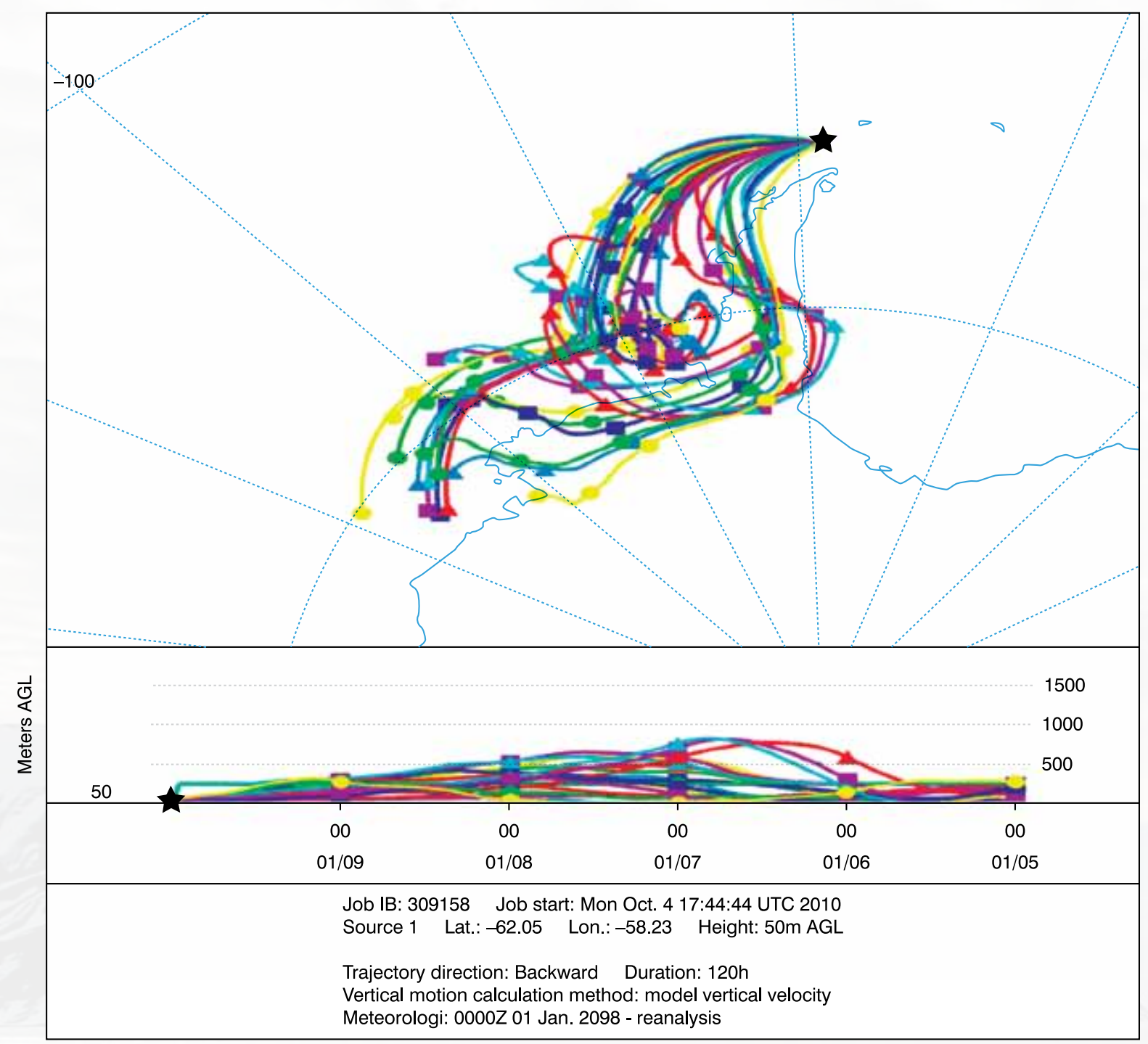

Figure 3. Back-trajectory model (Hyspit/NOAA), during the the increase of Levoglucosan levels over the King George Island in January 1998.

Version 3), a Gaussian Plume Model in a steady-state condition that can be used in the evaluation of pollutant concentrations and/or in the deposition fluxes from a great variety of complex sources (Vidal, 2008). In this study, the plume model was configured for a critical scenario whereby 3 scientific stations and 4 ships were operating simultaneously in Admiralty Bay. The result is shown in Figure 1 and considers an average distribution of local wind, topoghaphy and the predominant classes of stability. It can be observed that in these circumstances, apart from local impacts, an important part of Admiralty Bay receives the combined atmospheric impact of these pollutants sources.

\section{Chemical tracers: Levoglucosan}

Levoglucosan (1,6 anhydro- $\beta$-D-glucopyranose), the product of cellulose pyrolysis, has been studied as a forest and agricultural biomass burning tracer due to its resistance to weathering and its dispersion in the atmosphere during occurrences of slash-and-burn. Another potential source of levoglucosan in Antarctica is the practice of organic 


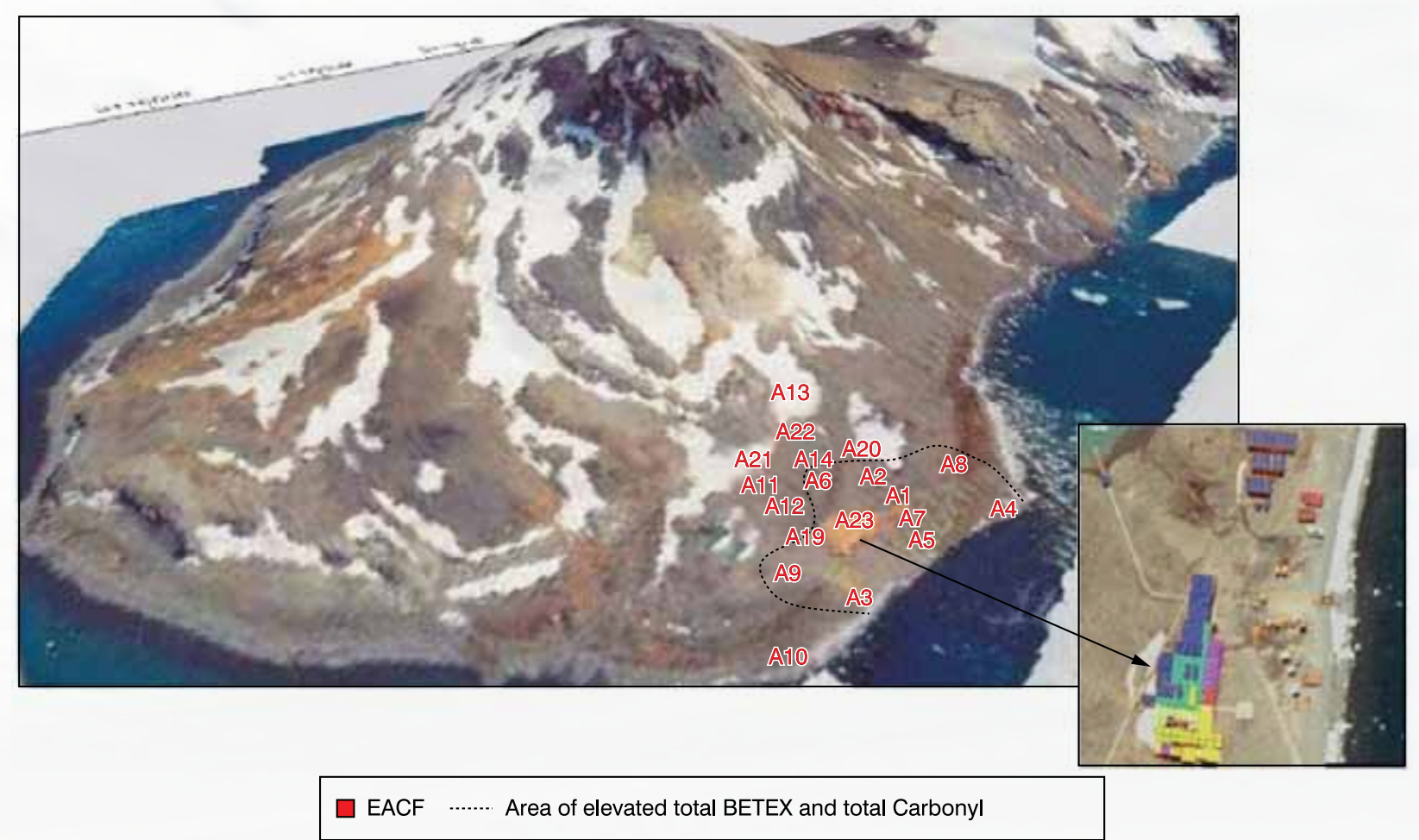

Figure 4. Spatial distribution of the atmospheric samples during the first phase of the 2009/2010 summer at EACF. The dotted contour line indicates where significant increases of BTEX and Carbonylic compounds were observed. The lower square close up detail, to the right, shows EACF and the reserve fuel tanks.

waste incineration by the research stations. An analysis undertaken concerning the filter samples in 1998, whose monitoring spanned a complete annual sequence, showed that the level of greater concentration of levoglucosan coincided with the period of greatest human activity at EACF, at which moments the incinerator is used with greater frequency. From the seasonal point of view, the peaks of Levoglucosan differ from the occurrence of peaks of the forest slash-and-burn, not only in South America/Africa, but also in terms of worldwide slash-and-burn, according to the database of the European Space Agency - ESA, Figure 2. Considering that the displacement time of the plumes of smoke from slash-and-burn between South America and the Antarctic Peninsula occur in approximately 7-15 days, the time lag observed does not justify a continental origin for the levoglucosan, making the incineration of organic waste at EACF the most probable cause.
Trying to corroborating the hypothesis concerning the relevance of the local sources related to levoglucosan, regarding long distance displacement, the Hysplit/NOAA model was used with in order to investigate the nature of the back-trajectories of the air masses, referring to the sample dates that show high concentrations. A typical structure is shown in Figure 3, calculated for January 2008. In this case, it was verified that during the periods of high level of Levoglucosan, the air masses that prevailed over the King George Island were basically from polar-oceanic nature, justifying, in principle, the influence of forest slash-andburn over that region.

\section{Carbonylic and monoaromatic hydrocarbons}

In general the main carbonylic compounds in the troposphere are formaldehyde, acetaldehyde and acetone, and the first is considered carcinogenic by IARC. The monitoring of these compounds is an American regulatory ruling by USEPA. In the vicinity of EACF, 14 air samples 

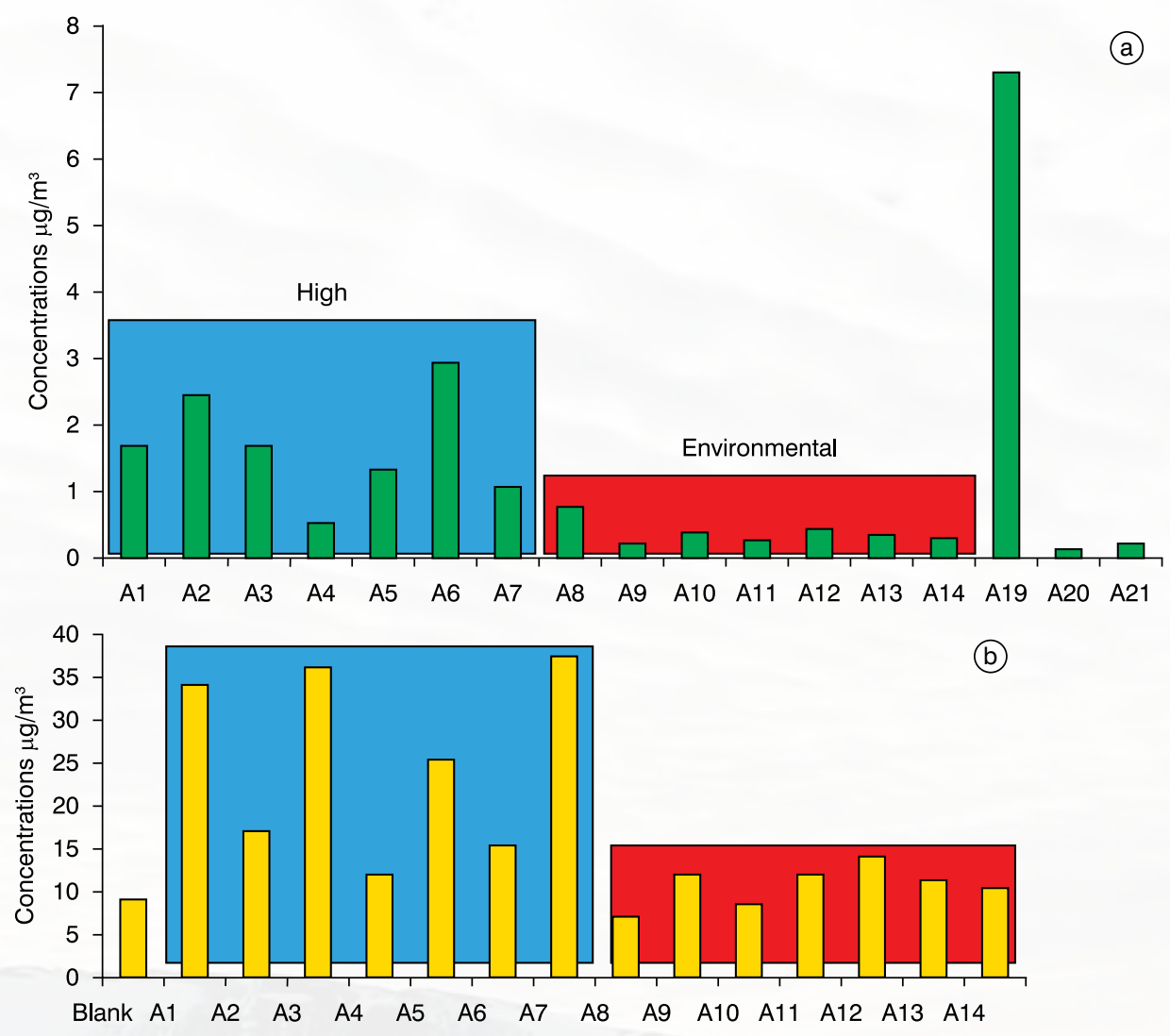

Figure 5. a) Total BTEX and b) Total Carbonyl. The colored rectangles distinct the samples with higher values and the environmental levels. The identification of the samples refers to Figure 4. Sampling station A19 was set close to the emission point.

were collected and analysed according to USEPA(1997) methodology. The results showed the presence of these compounds, mainly inside a 200-400 m radius from EACF (Figures 4 and 5). The same occurred for BTEX, aromatic hydrocarbons present in diesel and with high resistance to environmental degradation and and high volatility. In sub-polar environments the latter form becomes more persistent, since the low temperatures delay their degrading process. Among the 21 air samples analysed for BTEX, an analogue spatial distribution behaviour for the carbonylic compounds was observed.

A cluster analysis between the results of the atmospheric chemical pollutants and meteorological data obtained in situ (in the case, pressure, humidity, wind intensity, air temperature and solar radiation), indicated the presence of 3 groups when a tolerance limit of 0.35 was adopted; that is, a first group that relates pressure and relative humidity

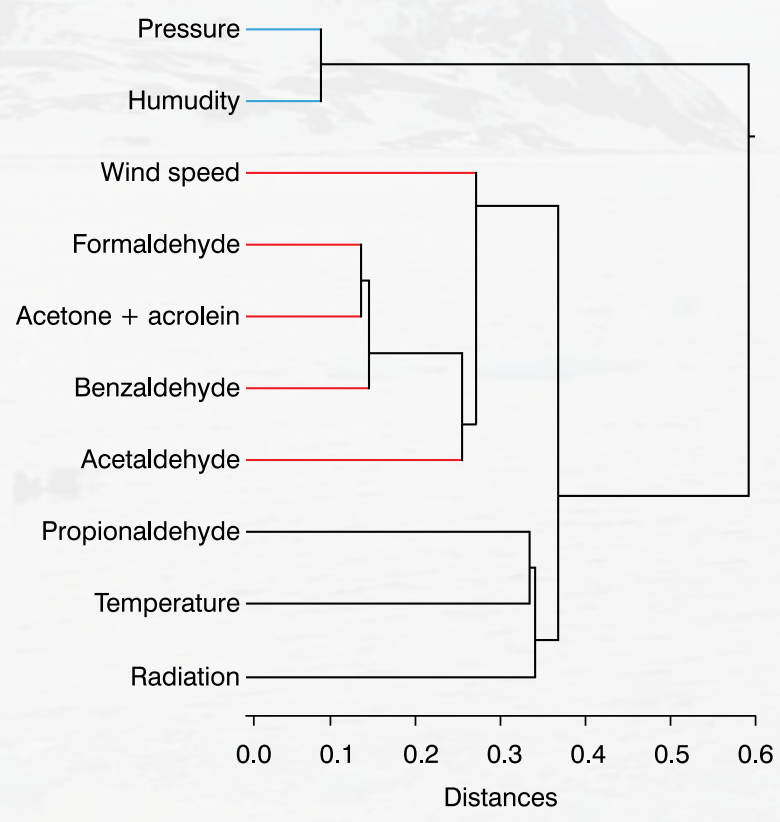

Figure 6. Cluster analysis of Carbonylic Compounds and meteorological data for the 2009 summer around EACF. 
which illustrates the dynamism of the frontal systems in the region, which carry oceanic humidity to King George Island. A second group that relates the air temperature and global solar radiation, as a result of heating up of the local atmosphere through the direct effect of solar radiation, and a third group that concentrates the greater part of its chemical compounds (with exception to propionaldehyde) grouped together with wind intensity which is a meteorological modulating parameter of the air concentrations. The result of the cluster (Figure 6) indicates the nature of the local emissions.

As a final remark, the EACF is potentially a source of fugitive emissions from fuel tanks. These refer to unintended release of gases from defective, vents, connections and pressure valves, the latter being a big problem for the petrochemical industry. Their control is usually associated to maintenance. In the case of storage and fuel supply, the question refers to the escape of gases through the vents and fuel tank entrances. In many European countries there is an environmental requirement that at the time of fuel transfers the saturated gases in the storage tanks shall be collected.
The fuel transfer into the storage tanks at EACF occur between the end of spring and the beginning of summer.

\section{Conclusion}

The samples analysed up to the present, clearly demonstrate an existing impact due to the use of fossil fuel and incineration of organic waste. However, this impact, from the atmospheric point of view, seems to be restricted, signicantly, to the occupational and infrastructure zones ( 200-400 $\mathrm{m}$ around EACF). The reason is probably the persistent strong local winds and the atmospheric stability pattern, important in the process of dispersion of gases and particulate material emitted by the EACF.

\section{Aknowledgments}

We kindly thank the Instituto Nacional de Ciência e Tecnologia Antártico de Pesquisas Ambientais (INCT-APA) and the grants CNPq/574018/2008-5 and FAPERJ/E-16/170.023/2008 that made possible this work. Also Dr. Neusa Paes Leme/INPE for her great help in the logistics and invitation to join INCT-APA.

\section{References}

USEPA. Compendium Method TO-11A. (1997). Determination of Formaldehyde in Ambient Air Using Adsorbent Cartridge Followed by High Performance Liquid Chromatography (HPLC). EPA-625/R-96/010b. Cincinnati, OH: U.S. Environmental Protection Agency.

Vidal, C.M.C. (2008). Descrição da Metodologia do Cálculo da Dispersão de Plumas Aplicada a um Complexo industrial Dissertação de Mestrado- Instituto de Química - UERJ.

Weber R.R. \& Montone, R.C. (2006). Gerenciamento Ambiental da Baía do Almirantado, Ilha Rei George- Antártica - Rede 2 - MMA 